\title{
Designs of rectangular-shaped planar inverted-F antennas at mobile operating frequencies with different ground plane techniques
}

\author{
Nurul Inshirah Mohd Razali, Norhudah Seman, Tien Han Chua \\ Wireless Communication Center, School of Electrical Engineering, Universiti Teknologi Malaysia, Malaysia
}

\begin{tabular}{|c|c|}
\hline Article Info & ABSTRACT \\
\hline Article history: & $\begin{array}{l}\text { This article presents the designs of planar inverted-F antennas (PIFAs) at } \\
\text { frequencies of } 0.835 \mathrm{GHz}, 0.9 \mathrm{GHz}, 1.8 \mathrm{GHz}, 1.9 \mathrm{GHz}, 2 \mathrm{GHz} \text {, and } 2.6 \mathrm{GHz} \text {. }\end{array}$ \\
\hline Received Oct 1, 2018 & Initially, the designs of rectangular-shaped PIFAs are determined through the \\
\hline Revised Dec 10, 2018 & parametric studies concerning the dimensions of the antenna's patch length, \\
\hline Accepted Jan 25, 2019 & $\begin{array}{l}\text { shorting plate, ground plane, and substrate. Afterward, rectangular-shaped } \\
\text { slots are introduced into radiating element of two antennas that operate at a }\end{array}$ \\
\hline Keywords: & $\begin{array}{l}\text { lower frequency range of less than } 1 \mathrm{GHz} \text {, to tune the resonant frequency to } \\
\text { the respective } 0.835 \mathrm{GHz} \text { and } 0.9 \mathrm{GHz} \text {. Different configurations of partial or }\end{array}$ \\
\hline Ground plane & full ground plane are implemented to improve the reflection coefficient, \\
\hline Mobile & $S_{11}$ performance to be below $-10 \mathrm{~dB}$ in both simulation and measurement. \\
\hline PIFA & $\begin{array}{l}\text { The proposed six PIFAs have gain that are greater than } 2 \mathrm{~dB} \text { with the nearly } \\
\text { omnidirectional radiation patterns. All the designs and analyses are }\end{array}$ \\
\hline $\begin{array}{l}\text { Rectangular } \\
\text { Slot }\end{array}$ & $\begin{array}{l}\text { performed using the CST Microwave Studio utilizing Rogers 4003C } \\
\text { substrate. }\end{array}$ \\
\hline
\end{tabular}

Copyright $\odot 2019$ Institute of Advanced Engineering and Science. All rights reserved.

\section{Corresponding Author:}

Norhudah Seman,

Wireless Communication Centre, School of Electrical Engineering,

Universiti Teknologi Malaysia,

81310 UTM Johor Bahru, Malaysia.

Email: huda@fke.utm.my

\section{INTRODUCTION}

The technological revolution in the world nowadays has discovered a lot of services and devices to assist people in their daily life, which one of them is wireless devices. Currently, wireless devices become essential in connecting plentiful users at anytime and anywhere, which require a low profile antenna. Planar inverted-F antenna (PIFA) can be categorized as one of the lowest profile antennas that used widely in a handheld wireless device that has several advantages of simple structure, small size, easy to fabricate and low manufacturing cost [1-4]. Furthermore, PIFA gives a smaller size compared to rod, monopole and helix antenna, which lead to easier locating and alignment between the components [4]. Hence, PIFA has become a popular antenna to be used for a portable wireless device such as a mobile phone that its design widely researched concerning all the wireless communication frequency between $835 \mathrm{MHz}$ and $2.6 \mathrm{GHz}$ [5-8].

Saraereh et. al in [5] proposed a design of PIFA by using air substrate that had a final dimension of $36 \mathrm{~mm}$ x $80 \mathrm{~mm}$. However, this work only concerned operating frequencies of $1.103 \mathrm{GHz}$ and $2.225 \mathrm{GHz}$. Another design was introduced in [6] utilizing air substrate with a dimension of $40 \mathrm{~mm}$ x $80 \mathrm{~mm}$. This design implemented a patch with a slot to tune the resonant frequency. Nevertheless, it only considered operating frequency that less than $1 \mathrm{GHz}$, which were $900 \mathrm{MHz}$ and $1800 \mathrm{MHz}$ that not covering all frequencies needed for the mobile phone. A design of PIFA with greater bandwidth was deliberated in [7] to cover UWB operation across $3.1 \mathrm{GH}-10.6 \mathrm{GHz}$. The design implemented a few slots on the patch that had a total dimension of $120 \mathrm{~mm}$ x $60 \mathrm{~mm}$, which can be considered quite large for the use in mobile phone applications 
that need compact size. Furthermore, it was not covering the concerned mobile frequencies below than 3 GHz. While another design of PIFA that reported in [8] implementing FR-4 substrate. It also employed a few slots to cover two operational bandwidths, which one of them had a range from $1.0785 \mathrm{GHz}$ to $1.325 \mathrm{GHz}$ and another one from $2.275 \mathrm{GHz}$ to $2.612 \mathrm{GHz}$ with reflection coefficient optimized at $-6 \mathrm{~dB}$. It had a dimension of $100 \mathrm{~mm} \times 41 \mathrm{~mm}$, which also considered quite large but still can be used for mobile phone use. However, the design did not involve all mobile operating frequency.

Thus, this article concerns the designs of PIFAs for the mobile operating frequencies below $3 \mathrm{GHz}$, which are $0.835 \mathrm{GHz}, 0.9 \mathrm{GHz}, 1.8 \mathrm{GHz}, 1.9 \mathrm{GHz}, 2 \mathrm{GHz}$, and $2.6 \mathrm{GHz}$. Rectangular-shaped patch is proposed with various ground plane configurations. Slots implemented to the radiating element to tune operating frequency to $0.835 \mathrm{GHz}$ and $0.9 \mathrm{GHz}$. These antennas are designed, simulated and optimized via the use of full electromagnetic wave simulator, CST Microwave Studio. The optimized designs are fabricated, where their performances are verified by measurement in the laboratory. Parametric studies are performed throughout the design processes to observe the effect of the width of the shorting plate, antenna patch length, substrate and ground plane size towards their resonant frequencies and antenna gain performance.

\section{PIFA DESIGN AND PARAMETRIC STUDY}

The proposed PIFA antenna design consists of a rectangular patch that acts as a radiating element on the top layer as shown in the respective perspective view and top view in Figure 1 and Figure 2. The antenna patch is placed at the edge of the antenna due to the existence of a shorting plate that needed to connect the patch and ground plane. While, three rectangular-shaped slots are implemented only to the radiating elements of $0.835 \mathrm{GHz}$ and $0.9 \mathrm{GHz}$ PIFA, to tune operating frequency to be less than $1 \mathrm{GHz}$. Whilst, different approach grounding techniques have been implemented, which are partial or full ground plane to achieve the desired performance of the designed PIFA. All PIFAs are designed by utilizing Rogers RO4003C substrate with a dielectric constant of 3.38, a thickness of $0.508 \mathrm{~mm}$, conductor coating of $0.017 \mathrm{~mm}$ and tangent loss of 0.0027 .

The rectangular patch has a dimension of length, Lp and width, Wp that can be designed based on the following (1) $[9,10]$ :

$$
L p+W p=\frac{\lambda}{4}
$$

where $\lambda$ is the wavelength that can be expressed as (2) [11]:

$$
\lambda=\frac{c}{f \sqrt{\varepsilon_{e}}}
$$

where $c, f$ and $\varepsilon_{e}$ are the speed of light, operating frequency and effective relative permittivity of the substrate, respectively. The effective relative permittivity of the substrate, $\varepsilon_{e}$ can be determined from (3) [11-14]:

$$
\varepsilon_{e}=\frac{\varepsilon_{r}+1}{2}+\frac{\varepsilon_{r}-1}{2} \frac{1}{\sqrt{1+12 \frac{d}{W p}}}
$$

where $d$ and $\varepsilon_{r}$ are substrate thickness and relative permittivity, accordingly. A shorting plate has a dimension of Ws x Ls x Ts. Where, Ws, Ls, and Ts are the respective width, length and thickness of the shorting plate. The shorting plate is located on the left side of the PIFA antenna. This shorting plate must be carefully placed to ensure both patch and ground plane are linked. As a suitable feeding is important to ensure a well-matched antenna to produce a good performance, a coaxial feeding technique is utilized in this design due to its simplicity in the positioning of the feed point to adjust the input impedance level $[8,15-17]$. The coaxial feed that consists of three layers, which are an inner conductor of a pin, dielectric and a conductor cover. The coaxial inner conductor, which is the pin is attached to the radiating patch, while the outer conductor is connected to the ground [18]. Hence, the coaxial feed is positioned close to the top left of the PIFA antenna, which offers the best performance for all the antennas, except antennas at frequencies $0.835 \mathrm{GHz}$ and $0.9 \mathrm{GHz}$. For antennas that operate less than $1 \mathrm{GHz}$, the feed has to be positioned close to the centre at the end of the top patch. Thus, it means the position of feed location is important to have a good matching and performance including reflection coefficient, $S_{11}$. 


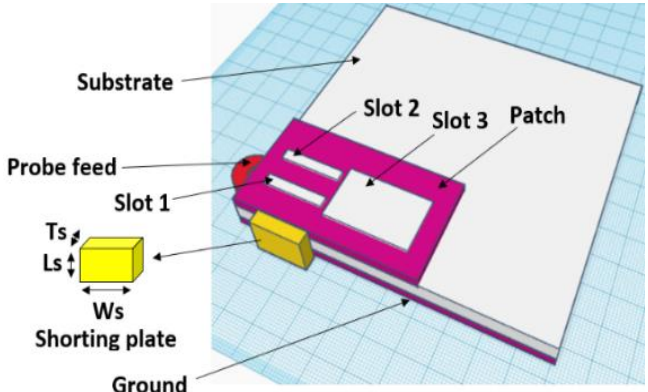

(a)

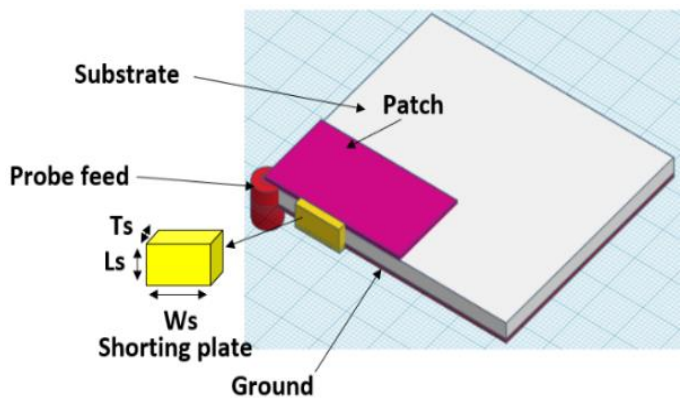

(b)

Figure 1. Perspective view of proposed PIFA design, which operates at: (a) $0.835 \mathrm{GHz}$ and $0.9 \mathrm{GHz}$, and (b) $1.8 \mathrm{GHz}, 1.9 \mathrm{GHz}, 2 \mathrm{GHz}$, and $2.6 \mathrm{GHz}$

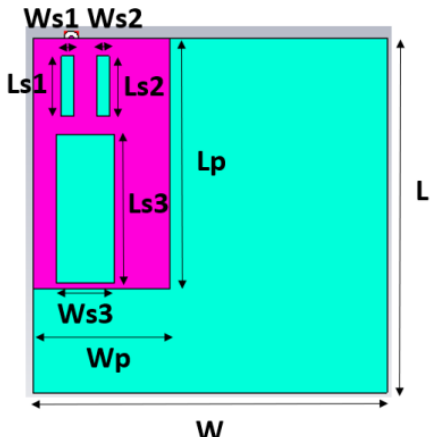

(a)

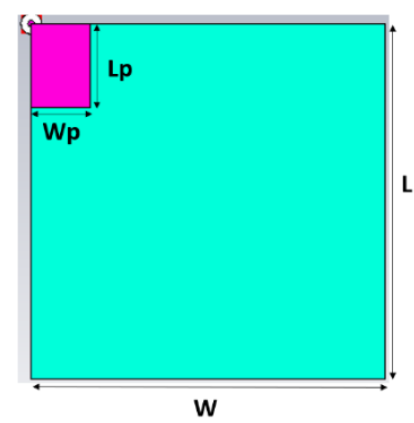

(d)

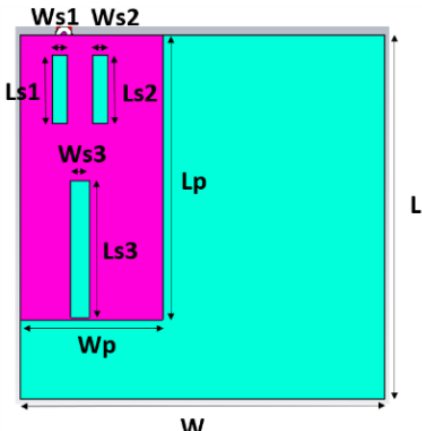

(b)

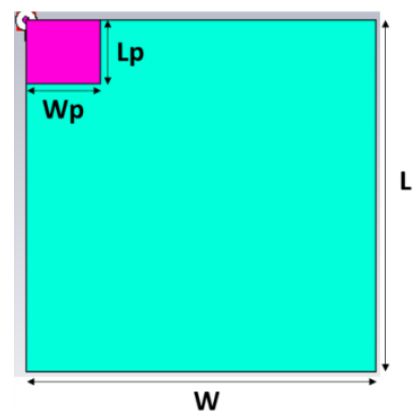

(e)

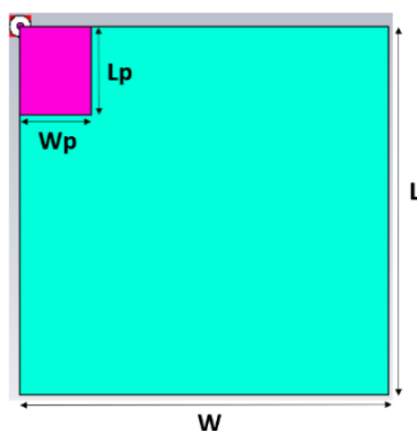

(c)

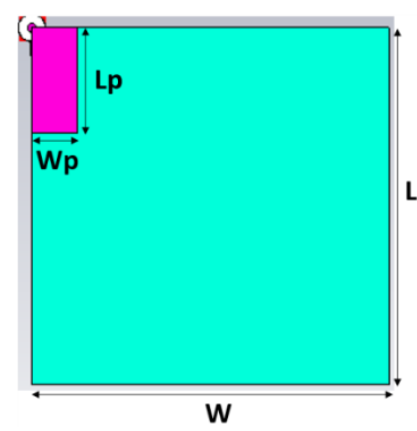

(f)

Figure 2. Top view of the proposed PIFA design: (a) $0.835 \mathrm{GHz}$ (b) $0.9 \mathrm{GHz}$, (c) $1.8 \mathrm{GHz}$, (d) $1.9 \mathrm{GHz}$, (e) $2 \mathrm{GHz}$, and (f) $2.6 \mathrm{GHz}$

A parametric study has been conducted on several antenna parameters including the size of the patch antenna, size of shorting plate, and size of substrate and ground plane. The parametric study is carried out to observe the performance of the antenna by focusing on the resonant frequency of each antenna. Firstly, the parametric study has been done on the size of the patch antenna, Lp x Wp. As initially, the PIFA patch, Lp x $\mathrm{Wp}$ is designed by using equation (1) for each antenna. However, these PIFAs with initial calculated Lp and $\mathrm{Wp}$, and initial size of shorting plate appear to have shifted resonant frequencies to the higher band from the designated $0.835 \mathrm{GHz}, 0.9 \mathrm{GHz}, 1.8 \mathrm{GHz}, 1.9 \mathrm{GHz}, 2 \mathrm{GHz}$, and $2.6 \mathrm{GHz}$. Thus, a few parametric studies are carried out to achieve the desired resonant frequency for each antenna. Firstly, the shorting plate size is varied to observe its effect on the resonant frequencies. Table 1 and Figure 4 show the parametric study on the size of the shorting plate. 


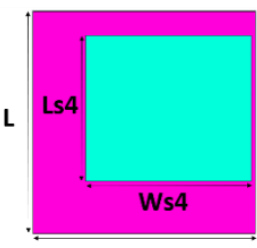

(a)

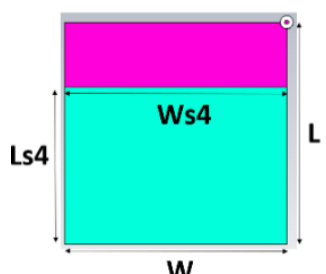

(b)

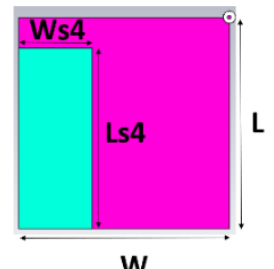

(c)

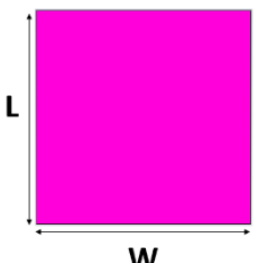

(d)

Figure 3. Bottom view of proposed PIFA design: (a) $0.835 \mathrm{GHz}$ and $0.9 \mathrm{GHz}$, (b) $1.8 \mathrm{GHz}$, (c) $1.9 \mathrm{GHz}$ and (d) $2 \mathrm{GHz}$ and $2.6 \mathrm{GHz}$

Table 1. The changes of resonant frequencies based on shorting plate width

\begin{tabular}{cc}
\hline $\begin{array}{c}\text { Width of shorting plate } \\
(\mathrm{mm})\end{array}$ & Frequency $(\mathrm{GHz})$ \\
\hline 2 & 3.180 \\
4 & 3.730 \\
6 & 4.075 \\
8 & 4.176 \\
10 & 4.176 \\
12 & 4.176 \\
\hline
\end{tabular}

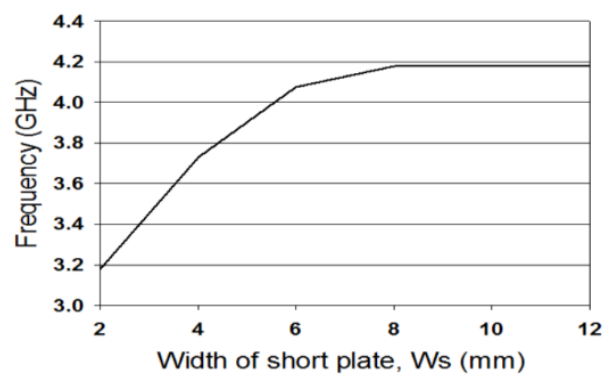

Figure 4. Graph of the width of shorting plate versus frequency

The width of the shorting plate, Ws is decreased from $12 \mathrm{~mm}$ to $2 \mathrm{~mm}$, while the thickness, Ts and length, Ls of shorting plate are fixed to $1 \mathrm{~mm}$ and $0.595 \mathrm{~mm}$, respectively. The variation of Ws from $12 \mathrm{~mm}$ to $2 \mathrm{~mm}$ is resulting in decreasing of the resonant frequency. The length of the current-line path increases with decreasing shorting plate width that leads to the decrement of the resonant frequency [19]. This can be used to initiate the desired resonant frequency that less than $3 \mathrm{GHz}$ for each antenna. Thus, $2 \mathrm{~mm}$ is chosen to be used in all designs as the minimum width of the shorting plate considering the fabrication limitation.

Next, to make the antennas' resonant frequencies become further decrease, a parametric study on the size of the patch antenna is executed, as the desired resonant frequencies for all antennas have not been achieved. The length of the patch antenna, Lp is varied, and the width of the patch, $\mathrm{Wp}$ is fixed to $7 \mathrm{~mm}$ to observe its effect on resonant frequency. This process is conducted to all six antennas and the outcome for all antennas are similar. Table 2 and Figure 5 show the correlation between the length of the patch antenna and the resonant frequencies. When the length of the patch is increased from $10 \mathrm{~mm}$ to $52 \mathrm{~mm}$ with fixed $\mathrm{Wp}$ of 7 $\mathrm{mm}$, the resonant frequency is decreasing, which is complying with the need to further decrease the resonant frequency of each antenna to be less than $3 \mathrm{GHz}$. The results depict the increment of antenna patch length has contributed in lowering the resonant frequency as PIFA is a quarter wavelength antenna, hence by increasing the size of antenna patch, the wavelength increases, which causes the resonant frequency to be decreased, which correlated to equation (2).

Table 2. The changes of resonant frequencies based on patch length

\begin{tabular}{cc}
\hline $\mathrm{Lp}(\mathrm{mm})$ & Frequency $(\mathrm{GHz})$ \\
\hline 10 & 3.7400 \\
15 & 2.7500 \\
20 & 2.0644 \\
25 & 1.6580 \\
30 & 1.3982 \\
35 & 1.1997 \\
40 & 1.0535 \\
45 & 0.9350 \\
52 & 0.8312 \\
\hline
\end{tabular}

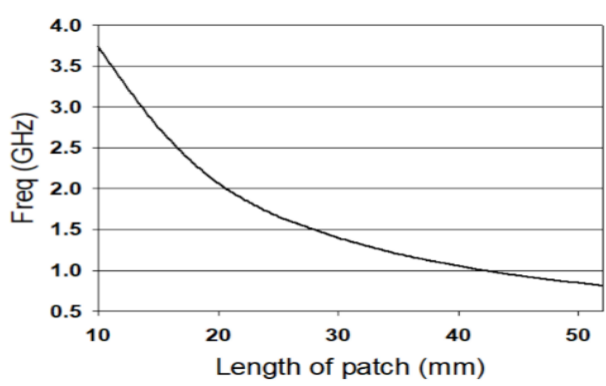

Figure 5. Graph of the length of patch versus frequency 
Afterward, the parametric study is continued specifically for $0.835 \mathrm{GHz}$ and $0.9 \mathrm{GHz} \mathrm{PIFA}$ concerning the implementation of three rectangular slots to tune to resonant frequencies to the designated $0.835 \mathrm{GHz}$ and $0.9 \mathrm{GHz}$, which unable to be achieved with just rectangular patch radiating element. These three rectangular slots are placed symmetrically to the radiating element as depicted in Figure 2 (a)-(b) that optimized accordingly to accomplish the designated resonant frequency. The slotted radiating patch has meandered the excited patch surface current paths and results in lowering of the resonant frequency [20-22]. The larger size of the single slot at the lower position results lower resonant frequency. On the other hand, the slots also provide better gain, directivity, reflection coefficient and bandwidth [20,23]. Consequently, the study is further continued on the effect of the ground size by considering both partial and full ground plane. For the partial ground plane, it can be obtained by implementing a slot, which the position of slot also affects the performance. Full ground plane is implemented for $2 \mathrm{GHz}$ and $2.6 \mathrm{GHz}$ PIFA design. However, full ground plane for $0.835 \mathrm{GHz}, 0.9 \mathrm{GHz}, 1.8 \mathrm{GHz}$, and $1.9 \mathrm{GHz}$ PIFA has resulted in worst performance of $S_{11}$ even though the resonant frequencies are achieved. Thus, the partial ground plane is introduced to 0.835 $\mathrm{GHz}, 0.9 \mathrm{GHz}, 1.8 \mathrm{GHz}$, and $1.9 \mathrm{GHz}$ PIFA for a better antenna performance, which provides a matching solution to the design [24]. Hence, the size and position of the slot for the partial ground plane are optimized to accomplish the best reflection coefficient, $S_{11}$ performance.

A further parametric study is then carried out on for the size of the substrate since all the initial designed antennas' gain do not achieve the goal, which is at least $2 \mathrm{~dB}$. The width, W and length, L of the substrate are varied to study their effect towards the antenna gain, which executed independently for each antenna to accomplish $2 \mathrm{~dB}$ gain. The effects on the antenna gain are observed and plotted in Figure 6 . From Figure 6, it shows that when the size of the substrate is increased, the realized antenna gain is also increasing, which this correlation also reported in [25]. $2.6 \mathrm{GHz}$ PIFA can be noted to have the highest maximum gain of $2.695 \mathrm{~dB}$ with substrate dimension of $53 \mathrm{~mm}^{2}$. Meanwhile, other PIFA antennas with lower operating frequency have lower gain compared to $2.6 \mathrm{GHz}$ PIFA. The maximum gain of the respective $0.835 \mathrm{GHz}, 0.9$ $\mathrm{GHz}, 1.8 \mathrm{GHz}, 1.9 \mathrm{GHz}$ and $2 \mathrm{GHz}$ PIFA are $2.096 \mathrm{~dB}, 2.146 \mathrm{~dB}, 2.193 \mathrm{~dB}, 2.072 \mathrm{~dB}$, and $2.028 \mathrm{~dB}$ with substrate dimension of $100 \mathrm{~mm}^{2}, 90 \mathrm{~mm}^{2}, 69 \mathrm{~mm}^{2}, 69 \mathrm{~mm}^{2}$, and $68 \mathrm{~mm}^{2}$, accordingly. In addition, it can be observed that to achieve the designated gain of $2 \mathrm{~dB}$, an antenna with lower operating has a larger size compared to the antenna with higher operating frequency. After all the parametric studies have been performed, the optimization is executed to have an optimal performance for all antennas. The finalized dimensions of six PIFAs are tabulated in Table 3.

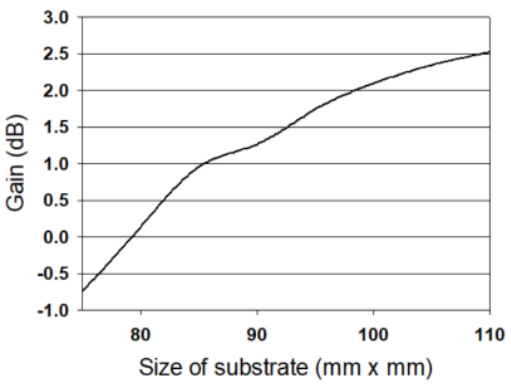

(a)

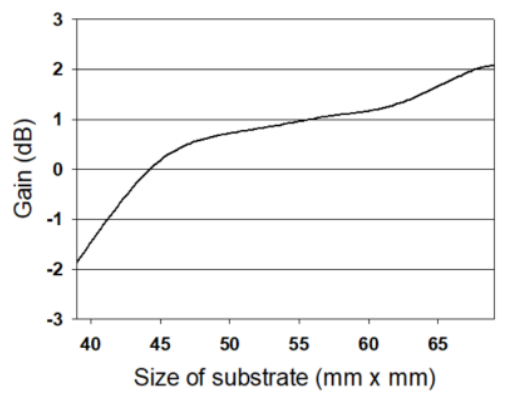

(d)

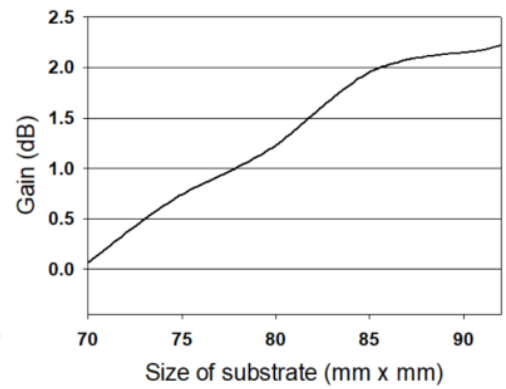

(b)

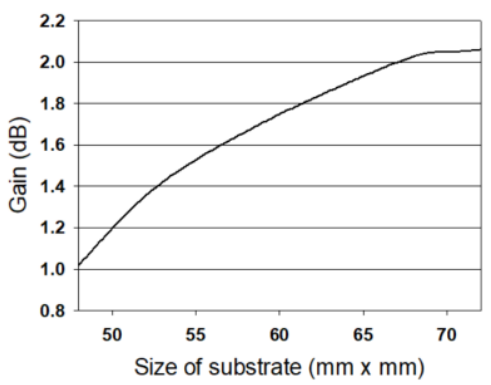

(e)

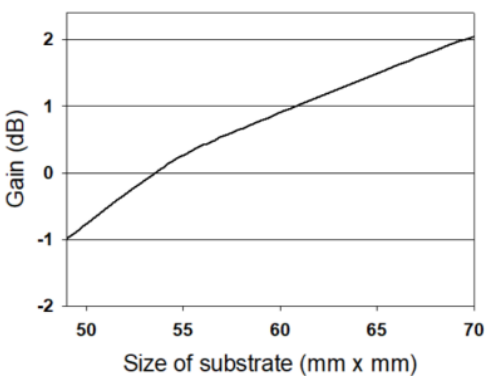

(c)

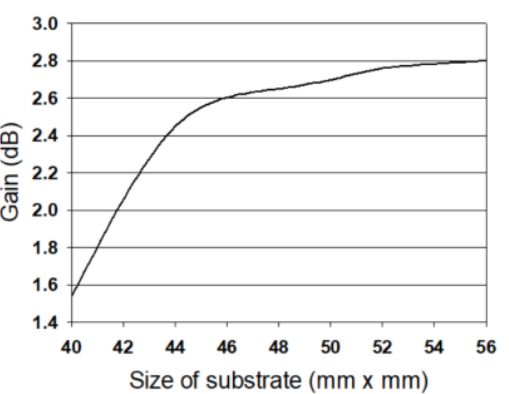

(f)

Figure 6. Size substrate versus gain of each PIFA that operating at: (a) $0.835 \mathrm{GHz}$ (b) $0.9 \mathrm{GHz}$ (c) $1.8 \mathrm{GHz}$ (d) $1.9 \mathrm{GHz}$ and (e) $2 \mathrm{GHz}$ (f) $2.6 \mathrm{GHz}$ 


\begin{tabular}{|c|c|c|c|c|c|c|c|}
\hline \multirow[b]{3}{*}{$\begin{array}{l}\text { Frequency } \\
\qquad(\mathrm{GHz})\end{array}$} & \multicolumn{6}{|c|}{ Table 3. Dimensions of PIFA antennas } & \multirow[b]{3}{*}{$\begin{array}{c}\text { Size of slot at } \\
\text { ground } \\
\text { (Ws } 4 \times \text { Ls4) }\end{array}$} \\
\hline & \multicolumn{6}{|c|}{ Dimension $(\mathrm{mm})$} & \\
\hline & $\begin{array}{l}\text { Size of shorting } \\
\text { plate } \\
\text { (Ws x Ls x Ts) }\end{array}$ & $\begin{array}{l}\text { Size of patch } \\
(\mathrm{Wp} \times \mathrm{Lp})\end{array}$ & $\begin{array}{c}\text { Size of substrate } \\
(\mathrm{W} \times \mathrm{L})\end{array}$ & $\begin{array}{c}\text { Size of slot at } \\
\text { patch } \\
\text { (Ws1 x Ls1) }\end{array}$ & $\begin{array}{c}\text { Size of slot at } \\
\text { patch } \\
\text { (Ws } 2 \times \text { Ls } 2)\end{array}$ & $\begin{array}{c}\text { Size of slot at } \\
\text { patch } \\
(\mathrm{Ws} 3 \times \text { Ls3) }\end{array}$ & \\
\hline 0.835 & $2 \times 0.595 \times 1$ & $38.60 \times 70.50$ & $100 \times 100$ & $3.5 \times 17$ & $3.5 \times 17$ & $16.5 \times 42$ & $82 \times 72$ \\
\hline 0.9 & $2 \times 0.595 \times 1$ & $35.20 \times 70.00$ & $90 \times 90$ & $3.5 \times 17$ & $3.5 \times 17$ & $4.5 \times 34$ & $82 \times 72$ \\
\hline 1.8 & $2 \times 0.595 \times 1$ & $13.37 \times 16.70$ & $69 \times 69$ & - & - & - & $69 \times 49$ \\
\hline 1.9 & $2 \times 0.595 \times 1$ & $11.57 \times 16.30$ & $69 \times 69$ & - & - & - & $24 \times 59$ \\
\hline 2.0 & $2 \times 0.595 \times 1$ & $14.43 \times 12.34$ & $68 \times 68$ & - & - & - & - \\
\hline 2.6 & $2 \times 0.595 \times 1$ & $6.80 \times 15.58$ & $53 \times 53$ & - & - & - & - \\
\hline
\end{tabular}

\section{RESULTS AND ANALYSIS}

The finalized designs of PIFAs are then fabricated, which the prototypes depicted in Figure 7. Following the fabrication, the prototypes are measured to verify their performance. All the results for both simulation and measurement for the proposed PIFAs are discussed in this section. Among the characteristic of the antenna, the power transmitted by the antenna is one of the most important characteristics, which can be seen through reflection coefficient, $S_{11}$ performance at the input port. As discussed in parametric studies of shorting plate width, patch length and the presence of slot on the patch and ground that resulting in changing of resonant frequency with the goal to accomplish $S_{11}$ performances below than -10 dB. The results of PIFAs' simulated and measured reflection coefficients are presented in Figure 8.

The proposed PIFAs exhibit the simulated reflection coefficients of $-19.88 \mathrm{~dB},-14.37 \mathrm{~dB},-21.68$ $\mathrm{dB},-14.8 \mathrm{~dB},-16.87 \mathrm{~dB}$, and $-30.15 \mathrm{~dB}$ for the respective resonant frequencies of $0.835 \mathrm{GHz}, 0.9 \mathrm{GHz}, 1.8$ $\mathrm{GHz}, 1.9 \mathrm{GHz}, 2 \mathrm{GHz}$, and $2.6 \mathrm{GHz}$. While their measured reflection coefficients also show the performance that less than $-10 \mathrm{~dB}$, which are $-15.45 \mathrm{~dB},-11.86 \mathrm{~dB},-18.17 \mathrm{~dB},-14.54 \mathrm{~dB},-15.26 \mathrm{~dB}$, and $-11.38 \mathrm{~dB}$, accordingly for each PIFA with the respective resonant frequency. The simulated and measured results are depicting that the proposed PIFAs have less than $10 \%$ reflected power which can be considered well perform. These PIFA reflection coefficients are summarized in Table 4. Besides reflection coefficient, gain is another characteristic that plays an important role in antenna's performance. PIFA gain is simulated at every resonant frequency, which the obtained results are listed in the following Table 4. All PIFAs have achieved the specified gain, which is at least $2 \mathrm{~dB}$. The highest gain is obtained by $2.6 \mathrm{GHz}$ PIFA, which $2.695 \mathrm{~dB}$. Whilst, other $0.835 \mathrm{GHz}, 0.9 \mathrm{GHz}, 1.8 \mathrm{GHz}, 1.9 \mathrm{GHz}$, and $2 \mathrm{GHz}$ PIFAs depict the respective gain of 2.096 $\mathrm{dB}, 2.146 \mathrm{~dB}, 2.193 \mathrm{~dB}, 2.072 \mathrm{~dB}$, and $2.028 \mathrm{~dB}$. The gain's good performance has been achieved by increasing the size of the substrate antenna as shown by the parametric study that plotted in Figure 6.

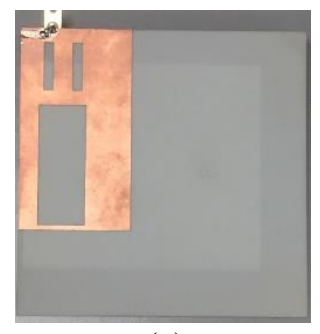

(a)

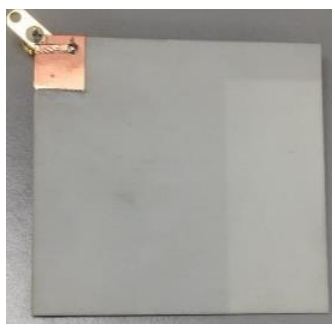

(d)

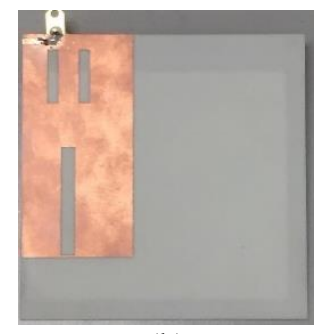

(b)

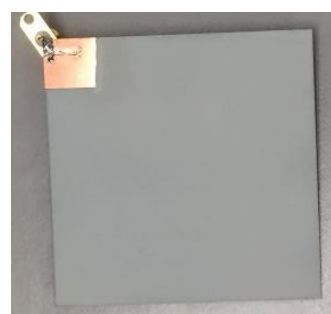

(e)

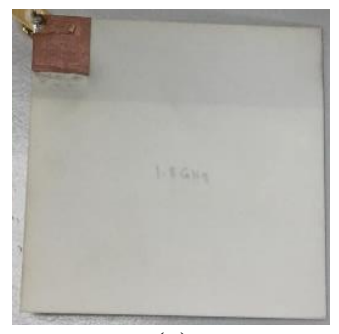

(c)

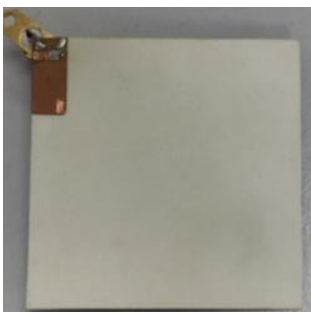

(f)

Figure 7. Fabricated PIFA antennas, which operate at respective operating frequency of: (a) $0.835 \mathrm{GHz}$ (b) $0.9 \mathrm{GHz}$ (c) $1.8 \mathrm{GHz}$ (d) $1.9 \mathrm{GHz}$ (e) $2 \mathrm{GHz}$ and (f) $2.6 \mathrm{GHz}$ 


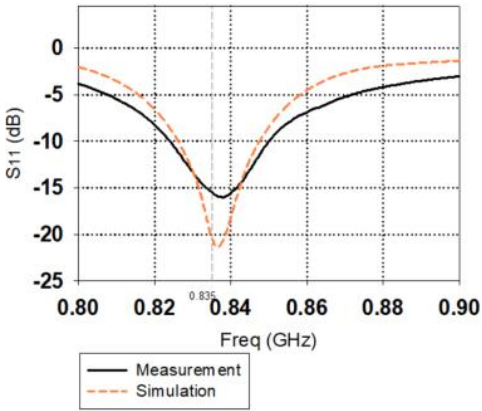

(a)

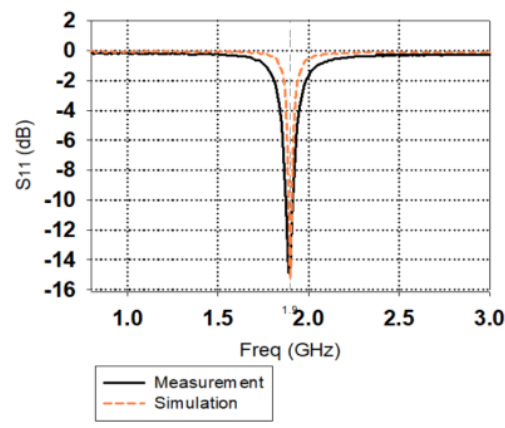

(d)

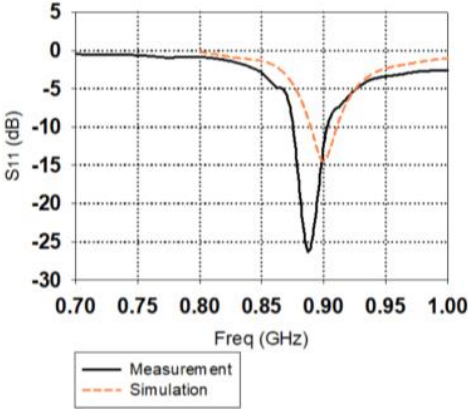

(b)

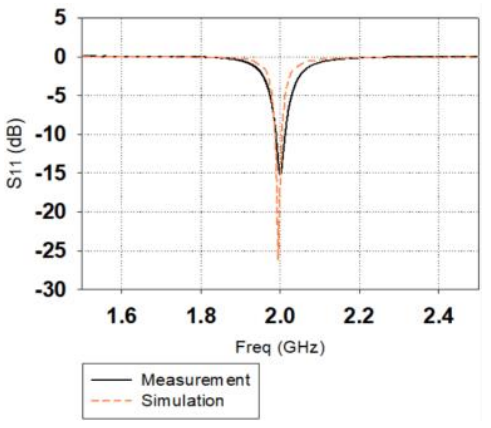

(e)

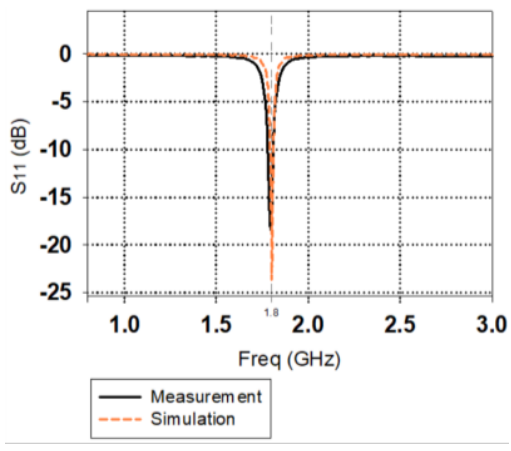

(c)

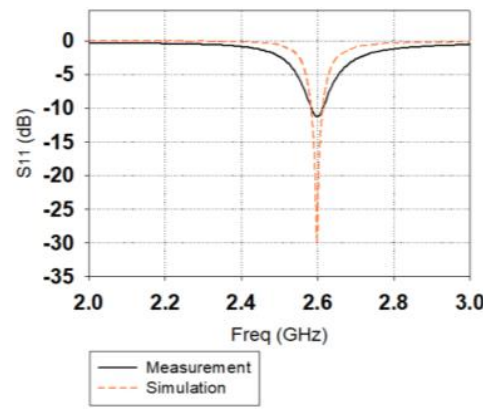

(f)

Figure 8. Simulation and measurement results of PIFA reflection coefficient, $S_{11}$ : (a) $0.835 \mathrm{GHz}$ (b) $0.9 \mathrm{GHz}$ (c) $1.8 \mathrm{GHz}$ (d) $1.9 \mathrm{GHz}$ (e) $2 \mathrm{GHz}$ and (f) $2.6 \mathrm{GHz}$

The next concern is the radiation pattern of the proposed PIFAs that assessed through simulation in CST Microwave Studio. Generally, the results of radiation patterns at E-plane for all six PIFAs, which presented in Figure 9 demonstrate a nearly omnidirectional beam, which indicating the proposed PIFAs are suitable for mobile antennas applications. The patterns are almost omnidirectional for $0.835 \mathrm{GHz}, 0.9 \mathrm{GHz}$, 1.8 GHz, $1.9 \mathrm{GHz}, 2 \mathrm{GHz}$ and $2.6 \mathrm{GHz}$ PIFAs, which show that the proposed PIFAs have performed well at all the operating frequencies.

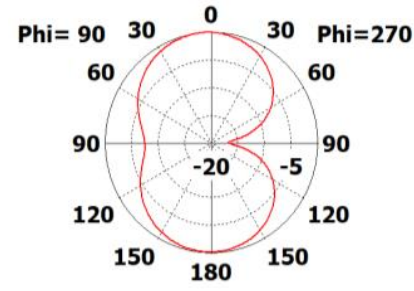

(a)

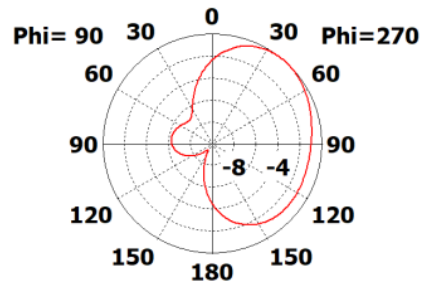

(d)

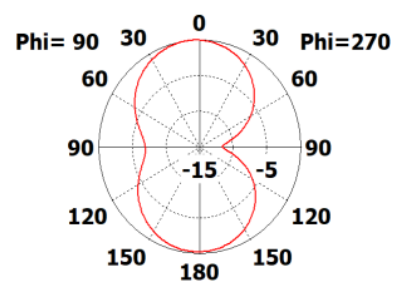

(b)

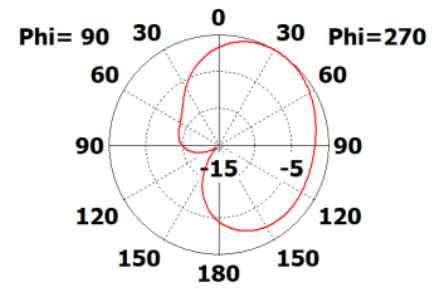

(e)

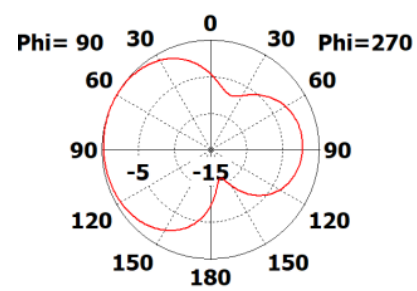

(c)

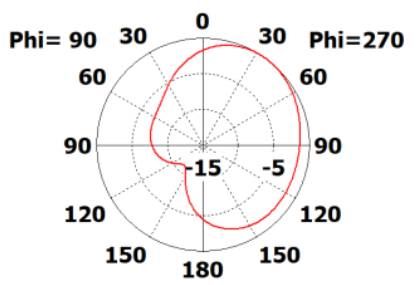

(f)

Figure 9. Radiation patterns of the PIFAs that operate at: (a) $0.835 \mathrm{GHz}$ (b) $0.9 \mathrm{GHz}$ (c) $1.8 \mathrm{GHz}$ (d) $1.9 \mathrm{GHz}$ (e) $2 \mathrm{GHz}$ and (f) $2.6 \mathrm{GHz}$ 
$\underline{\text { Table 4. Performances of PIFAs' reflection coefficients, } S_{11} \text { and gains }}$

\begin{tabular}{cccc}
\hline $\begin{array}{c}\text { Frequency } \\
(\mathrm{GHz})\end{array}$ & Simulation & $S_{11}(\mathrm{~dB})$ & Gain $(\mathrm{dB})$ \\
\hline 0.835 & -19.88 & -15.45 & 2.096 \\
0.9 & -14.37 & -11.86 & 2.146 \\
1.8 & -21.68 & -18.17 & 2.193 \\
1.9 & -14.80 & -14.54 & 2.072 \\
2.0 & -16.87 & -15.26 & 2.028 \\
2.6 & -30.15 & -11.38 & 2.695 \\
\hline
\end{tabular}

\section{CONCLUSION}

The designs of PIFAs that operated at the respective resonant frequencies of $0.835 \mathrm{GHz}, 0.9 \mathrm{GHz}$, $1.8 \mathrm{GHz}, 1.9 \mathrm{GHz}, 2 \mathrm{GHz}$, and $2.6 \mathrm{GHz}$ have been presented. Parametric studies have been performed on several antenna design parameters to achieve the optimal performance concerning the resonant frequencies and the gain. The parametric study results concluded that the size of the patch antenna and shorting plate on patch and ground of antenna have affected the resonant frequencies, while the size of substrate and ground have affected the antenna gain performance. The presence of slots at the radiating element has enabled the tuning of resonant frequency to be lower than $1 \mathrm{GHz}$, which are $0.835 \mathrm{GHz}$ and $0.9 \mathrm{GHz}$. Meanwhile, the design also considered the full and partial ground plane. The existence of the partial ground for $0.835 \mathrm{GHz}$, $0.9 \mathrm{GHz}, 1.8 \mathrm{GHz}$, and $1.9 \mathrm{GHz}$ PIFA have improved matching that allows for better performance of reflection coefficient. The proposed PIFAs have reflection coefficients less than $-10 \mathrm{~dB}$, gain better than $2 \mathrm{~dB}$ and nearly omnidirectional radiation pattern. Therefore, the proposed PIFAs with different ground plane techniques in this article exhibit suitability for mobile applications.

\section{ACKNOWLEDGEMENTS}

This work was supported by Ministry of Education Malaysia (MOE) and Universiti Teknologi Malaysia (UTM) through Flagship, HiCoE, PRGS and FRGS Grant with the respective vote number of 03G41, 4J212 and 4J216, 4L684 and 5F048.

\section{REFERENCES}

[1] O. Saraerah, et al., "Simulation and experimental SAR and efficiency study for a dual-band PIFA handset antenna (GSM 900/DCS 1800) at varied distances from a phantom head," IEE Antenna Measurements and SAR, 2004.

[2] B. Li, et al., "Six-band PIFA with Low SAR Value in Mobile Phone Applications," International Conference on Microwave and Millimeter Wave Technology, pp. 2-5, 2012.

[3] M. A. Rahman, et al., "Performance analysis of a planar inverted-F antenna (PIFA) including human interaction," Int. Conf. Informatics, Electron. Vision, pp. 1-5, 2013.

[4] N. Kumar, et al., "Study of Planar Inverted-F Antenna (PIFA) for Mobile Devices," Int. J. Electron. Commun. Technol., pp. 83-85, 2013.

[5] N. Chattoraj, et al., "Design of a Novel Dual - Band Planar Inverted F - Antenna for Mobile Radio Applications," J. Microwaves, Optoelectron. Electromagn. Appl., vol. 13, pp. 177-184, 2014.

[6] Y. Ben and Z. Hasan, "Planar Inverted-F Antenna Design for GSM900 and GSM1800 Frequency Bands for Mobile Handset," Int. J. Recent Dev. Eng. Technol, vol. 5, pp. 9-12, 2016.

[7] S. Jegadeesan, et al., "Ultra wideband PIFA antenna with supporting GSM and WiMAX for mobile phone applications," Int. Conf. Adv. Comput. Commun. Technol., pp. 15-20, 2015.

[8] S. Thavakumar and M. Susila, "Design of Multi Resonant PIFA Antenna for Mobile Telecommunication Networks," International Conference on Wireless Communications, Signal Processing and Networking, pp. 2462 2465, 2017.

[9] H. T. Chattha, et al., "An empirical equation for predicting the resonant frequency of planar inverted-F antennas," IEEE Antennas Wirel. Propag. Lett., vol. 8, pp. 856-860, 2009.

[10] N. Inshirah, et al., "Design and Specific Absorption Rate of $2.6 \mathrm{GHz}$ Rectangular- Shaped Planar Inverted-F Antenna," Indones. J. Electr. Eng. Comput. Sci., vol. 10, pp. 741-747, 2018.

[11] D. M. Pozar, "Microwave Engineering Third Edition," Wiley \& Sons, 2004.

[12] S. Elajoumi, et al., "Microstrip Rectangular Monopole Antennas with Defected Ground for UWB Applications," International Journal of Electrical and Computer Engineering, vol. 7, pp. 2027-2035, 2017.

[13] B. Garg and D. Saleem, "Innovative Double H Metamaterial Structure for Amelioration in Patch Antenna Parameters," vol. 2, pp. 278-285, 2013.

[14] S. Shawalil, et al., " $2.45 \mathrm{GHz}$ wearable rectenna array design for microwave energy harvesting," Indones. J. Electr. Eng. Comput. Sci., vol. 14, pp. 677-6877, 2019. 
[15] S. Bisht, et al., "Study The Various Feeding Techniques of Microstrip Antenna Using Design and Simulation Using CST Microwave Studio," International Journal of Emerging Technology and Advanced Engineering, vol. 4, pp. 318-324, 2014.

[16] D. D. Verma, et al., "Design of Coaxial Feed Microstrip Antenna by inserting P-I-N Diode to Improve Return Loss and Gain," International Journal of Current Engineering and Technology, vol. 6, pp. 897-899, 2016.

[17] R. Garg, et al., "Microstrip Antenna Design Handbook," Artech House, 2001.

[18] C. A. Balanis, "Antenna Theory," Third Edition, John Wiley \& Sons, Inc., Hoboken, New Jersey, 2005.

[19] H. Chen, et al., "Parametric study on the characteristics of planar inverted-F antenna," IEE Proceedings Microwaves, Antennas and Propagation, vol. 152, pp. 534-538, 2005.

[20] P. A. Ambresh, et al., "Effect of Slots on Microstrip Patch Antenna Characteristics," International Conference on Computer, Communication and Electrical Technology, pp. 239-241, 2011.

[21] R. Kumar, et al., "Effect of Slots in Ground Plane and Patch on Microstrip Antenna Performance," International Journal of Recent Trends in Engineering, vol. 2, pp. 1-4, 2009.

[22] A. H. Al, "PIFA Antenna Design for 4G Wireless Communications," International conferences on Information Technology, Information Systems and Electrical Engineering, pp. 188-191, 2017.

[23] M. John and S. Rodrigues, “Antenna Operated in ISM Band using RT-Duroid Substrate," pp. 3076-3080, 2016.

[24] M. Jusoh, "A Compact Size Antenna with High Gain Enhancement for IEEE 802.15.3," IEEE Symposium on Wireless Technology and Applications, pp. 120-123, 2011.

[25] V. Sipal, et al., "Effect of substrate dimensions on zeroth-order resonator antennas," IEEE Antennas Wirel. Propag. Lett, vol. 9, pp. 107-109, 2010.

\section{BIOGRAPHIES OF AUTHORS}
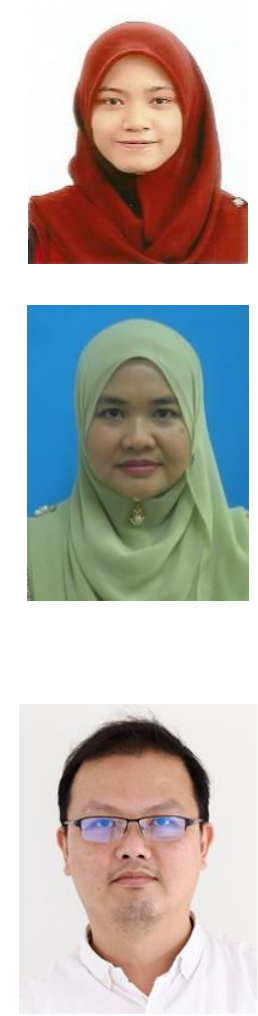

Nurul Inshirah Mohd Razali is a student of Master of Philosophy in Electrical Engineering from Wireless Communication Centre, Universiti Teknologi Malaysia. Inshirah has completed her degree in Bachelor of Electrical-Electronic Engineering from Universiti Teknologi Malaysia. Her current area of interest is in Specific Absorption Rate (SAR) investigation on PIFA antenna

Norhudah Seman received the B. Eng. in Electrical Engineering (Telecommunications) degree from the Universiti Teknologi Malaysia, Johor, Malaysia, in 2003 and M.Eng. degree in RF/Microwave Communications from The University of Queensland, Brisbane, St. Lucia, Qld., Australia, in 2005. In September 2009, she completed her Ph.D. degree at The University of Queensland. Currently, she is an Associate Professor and Director (Communication Engineering) in School of Electrical Engineering and Research Fellow in HiCoE Wireless Communication Centre (WCC), Universiti Teknologi Malaysia. Her research interests concern the design of microwave/millimeterwave devices for biomedical and industrial applications, effects of electromagnetic field radiation including specific absorption rate (SAR), and mobile communications.

Tien Han Chua received both the B.Sc. (Honours) degree in Electrical engineering (First Class) and the Master of Electrical Engineering in Wireless Engineering from the Universiti Teknologi Malaysia in 2003 and 2007, respectively. Tien Han was a Tutor (2005-2007) and then a Lecturer (2007-present) at the Faculty of Electrical Engineering, Universiti Teknologi Malaysia. His research interests include broadband fixed wireless access systems, radio propagation, channel modelling and measurement. 